\section{COMPLETE CONTROL OF THE FINISHED PROSTHESIS}

The CEREC 3D CAD/CAM System takes an optical impression of the preparation and the antagonist, resulting in probably the most accurate impression you will ever have taken. To allow you complete control of the finished prosthesis you specify the positions of the margins and the proximal contacts. The CEREC system goes on to swiftly fabricate the crown, inlay, onlay or veneer accurately, quickly and to the highest quality. CEREC automatically accurately computes the occlusal contacts resulting in the perfect fit.

The CEREC 3D CAD/CAM System will help you to produce probably the best ceramic restorations possible. The fit will be superb as the margin for error has been removed; the function, wear, durability and aesthetics of a CEREC prosthesis is second to none. In addition, this hi-tech piece of equipment allows you to place the new prosthesis in the same visit saving you and your patient time and laboratory fees and any embarrassment at having to wear a temporary.

To find out how the Sirona team can directly support your practice and for a demonstration of the CEREC 3D system call Sirona Dental Systems Limited on 0845 0715040 or visit www.sironadental.co.uk.

\title{
THE INS AND OUTS OF INCORPORATION
}

Incorporation is a complex procedure, but one that is becoming increasingly popular as professionals become aware of its many tax advantages. However, it is not without its drawbacks and many associate dental practitioners considering incorporation should know that by doing so, they will no longer qualify for the NHS pension and all the benefits that it provides. This includes life cover, which could particularly affect older professionals and high NHS earners.

To qualify for an NHS pension, you need to be an indi- vidual practitioner or have a contract with an NHS body. This is not the case when you become incorporated as the contract is held with the principal or the principal's limited company. Therefore, unless the associate maintains a contract in their own name as an individual, they would fail to meet the criteria for an NHS pension scheme.

Before embarking on the journey towards becoming a limited company, it is advisable to obtain guidance from money4dentists. With over 55 years' experience, money4dentists can provide you with the very best independent financial advice, tailored to the dental profession, and their dedicated team can ensure you succeed in all your professional endeavours.

For more information call 0845345 5060, email info@money4dentists.com or visit www.money4dentists.com.

\section{STRONG, FATIGUE-RESISTANT FILES}

The ProTaper Next file system from DENTSPLY has a unique off-centre, rectangular crosssection that gives the file a swaggering motion for superior canal shaping and debris removal. It also comes with NiTi M-Wire technology that makes its files more resistant to cyclic fatigue.
The biggest advantage of DENTSPLY's ProTaper Next file system is the added simplicity and efficiency of the files. Most canals can be prepared with two rotary files, and the off-centre design of the files' cross-sectional bulk leads to greater debris removal and canal shaping from the 'swaggering' motion of the rotating files. As always with DENTSPLY materials, you can be assured of excellent quality.

For a streamlined file system that gives consistently excellent canal preparation even in complex cases, turn to ProTaper Next.

Visit www.dentsply.co.uk or call 08000723313.

Earn Rewards against purchases at www. dentsplyrewards.co.uk. Access webinars and product demonstrations and earn CPD at www.dentsplyacademy.co.uk.

\section{EASILY IDENTIFY WHAT YOU WANT}

Quality Endodontic Distributors have recently launched the 11th edition of their Endodontic Specialist Catalogue with a distinctive new cover.

Laid out in a very clear and concise format, with drop down style headings which mimic their online catalogue with its built-in ordering facility, it makes it extremely easy to locate and identify precisely what you want and need.

The 11th edition includes all QED's established products plus many new additions, including an extended range of high performance Own Brand
Consumables, and the complete Reciproc range. Illustrated throughout, with every item coded and priced, QED believe it is the easiest endodontic catalogue to use and that every practice should have one.

To obtain your copy telephone 01733 404999, email sales@ qedendo.co.uk, visit www. qedendo.co.uk or contact your local QED Salesperson.

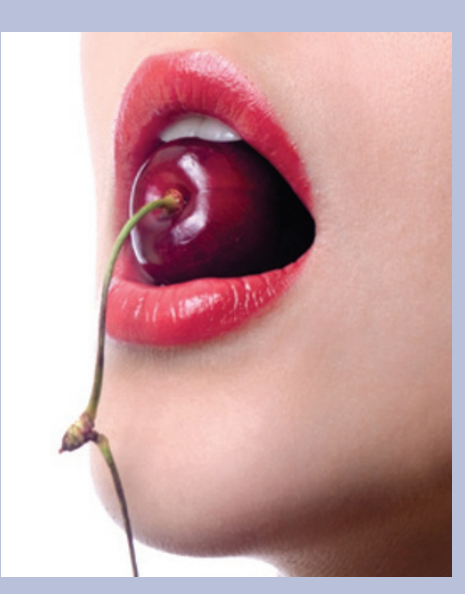

